\title{
REDUÇÃO DE AMIDAS POR BORANOS
}

\author{
Antônio Flávio de Carvalho Alcântara e Hiléia dos Santos Barroso \\ Departamento de Química, Instituto de Ciências Exatas, Universidade do Amazonas, 69073-000 Manaus - AM \\ Dorila Piló-Veloso \\ Departamento de Química, Instituto de Ciências Exatas, Universidade Federal de Minas Gerais, 31270-901 Belo Horizonte - MG
}

Recebido em 27/3/01; aceito em 25/7/01

\begin{abstract}
REDUCTION OF AMIDES BY BORANES. Despite the fact that boranes are frequently used in amide reductions, the reaction mechanisms of the involved are note well known. This work presents the results of a bibliographic search on probable amide reduction mechanisms and an analysis of the existing literature. Steric and electronic effects were considered in light of reactivity since it could be concluded that the formation of intermediates and products depends mainly on the substitution patterns of both the boron and nitrogen atoms. Otherwise, results described in the literature for the reactions of boranes, sodium borohydride, lithium aluminum hydride, alkylboranes or haloboranes with others functional groups such as carboxylic acids, esters, ketones and alkenes were analysed with the aim to obtain something about the $\mathrm{N}$-substituted amide reactions employing boranes.
\end{abstract}

Keywords: amides; reactivity of boranes; reduction.

\section{INTRODUÇÃO}

Amidas estão envolvidas em vários processos químicos e biológicos e têm sido empregadas em diversas classes de medicamentos como hipnóticos (zolpidem, zopiclone e acecarbromal), anticonvulsantes (carbamazepina, felbamato e progabida), tranqüilizantes (metilprilona e glutetimida), relaxantes musculares (alildietilacetamida, valnoctamida e oxanamida) e antivirais (AZT e ribavirin) ${ }^{1-3}$. Além disto, as amidas são empregadas também na síntese de agentes radiofarmacêuticos em medicina nuclear ${ }^{4}$.

De um modo geral, as propriedades químicas e biológicas das amidas estão relacionadas com a ordem da ligação carbono-nitrogênio, a qual expressa a deslocalização eletrônica entre os heteroátomos, sendo influenciada por fatores estéricos e eletrônicos dos grupos substituintes presentes tanto no nitrogênio quanto no carbono carbonílico. Devido à deslocalização eletrônica, essa ligação (denominada também de ligação peptídica) apresenta um alto grau de rigidez, com barreiras de energia rotacional variando entre 50 e $100 \mathrm{~kJ} / \mathrm{mol}^{5,6}$. A rigidez da ligação carbono-nitrogênio proporciona uma planaridade ao grupo amido em peptídeos e proteínas, a qual, somada aos efeitos de ligações de hidrogênio intramoleculares, determina formas estruturais helicoidais (Figura 1).

Nos processos químicos, as reduções de amidas têm sido muito empregadas no desenvolvimento de metodologias para formação de aminas, substâncias também importantes quimicamente ${ }^{8}$. Os procedimentos utilizados para reduções de amidas podem ser agrupados em quatro tipos: reações eletroquímicas; reações com metais; reduções nucleofílicas e reduções eletrofílicas.

As reações eletroquímicas e aquelas envolvendo metais são dependentes das condições de reação ${ }^{9,10}$, podendo levar à formação competitiva entre aminas, aldeídos ou álcoois ${ }^{11-17}$. As reduções nucleofílicas, empregando principalmente boro-hidreto de sódio $\left(\mathrm{NaBH}_{4}\right)$, hidreto de lítio e alumínio $\left(\mathrm{LiAlH}_{4}\right)$ e seus derivados ${ }^{18-28}$, proporcionam, além de aminas, a formação de outros produtos de reação. Assim, tris-(dialquilamino)-alumino-hidreto de lítio reduz

\footnotetext{
* e-mail: afcalcan@dedalus.lcc.ufmg.br
}

seletivamente amidas primárias e terciárias aos aldeídos correspondentes (Equação 1) ${ }^{29}$. Apesar de reduzirem as amidas quantitativamente, os redutores nucleofílicos apresentam, em muitos casos, aplicações limitadas em sínteses pois são redutores muito fortes, reagindo não especificamente com substâncias polifuncionais.

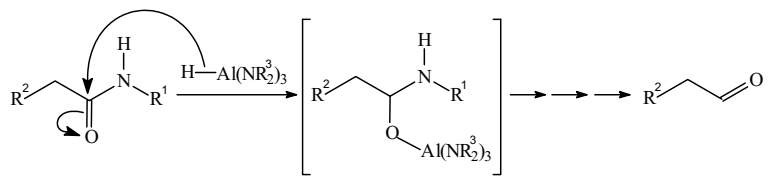

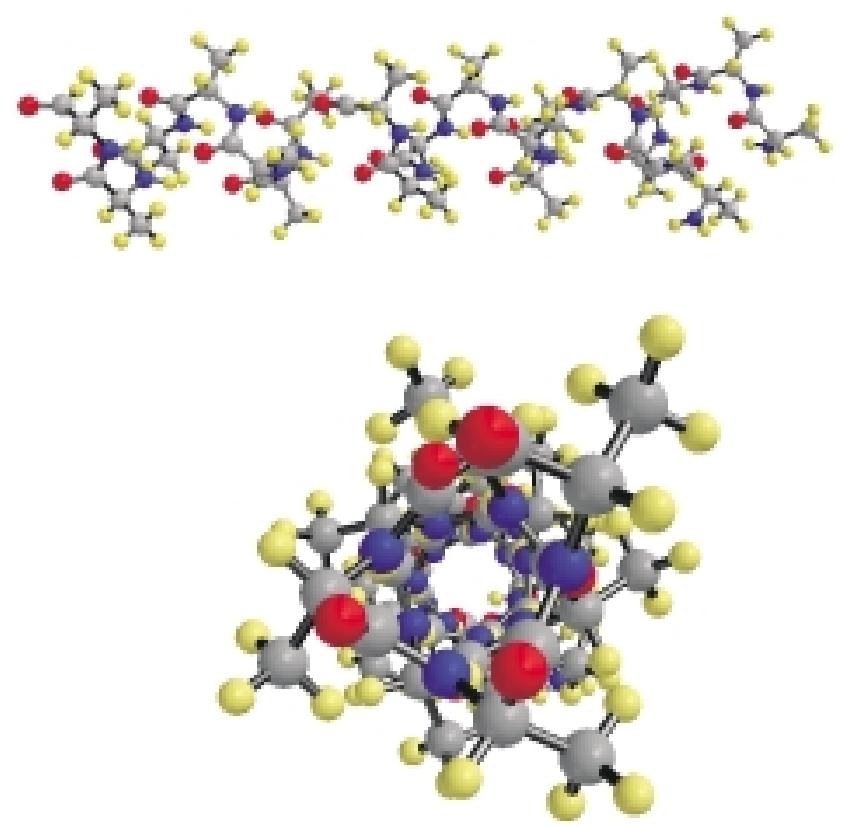

Figura 1. Visão lateral (superior) e frontal (inferior) de uma seqüência de 21 unidades de isoleucina que ilustra a forma helicoidal de proteínas, sendo $H$ (amarelo), C (cinza), O (vermelho) e $N$ (azul). Estrutura gerada empregando o método semi-empírico $A M 1^{7}$ 
A redução de amidas envolvendo redutores eletrofílicos, principalmente borano $\left(\mathrm{BH}_{3}\right)$ e diborano $\left(\mathrm{B}_{2} \mathrm{H}_{6}, \mathrm{DB}\right)$, alano $\left(\mathrm{AlH}_{3}\right)$ e seus derivados ${ }^{19,30-34}$, levam normalmente à formação seletiva de aminas em condições brandas de reação (Equação 2) ${ }^{35,36}$. Apesar da vasta aplicabilidade dos boranos nessas reduções, a literatura não descreve as etapas de reação e os mecanismos completos pois, em muitos casos, os trabalhos são oriundos de patentes, que apresentam os resultados de forma resumida e descritiva. Em algumas publicações são encontradas proposições de detalhes mecanísticos limitados às especificidades de cada reação. Entretanto, não consideram normalmente os efeitos da estrutura dos reagentes e do grau de $\mathrm{N}$-substituição nas amidas. Neste contexto, a fim de reunir informações sobre os mecanismos de reduções de amidas por boranos, foi publicado anteriormente um trabalho sobre redução seletiva de haloamidas a haloaminas ${ }^{37}$. Dando prosseguimento ao tema proposto, este trabalho apresenta de forma sistemática um levantamento bibliográfico sobre as etapas das reações de amidas com boranos. Além disto, são descritas também uma série de reações de boranos, boro-hidreto de sódio, hidreto de lítio e alumínio, haloboranos ou alquilboranos com outros grupos funcionais, tais como ácidos carboxílicos, ésteres, alquenos e cetonas, o que permitirá, por analogia, inferir sobre os mecanismos da reação destes reagentes com amidas diferentemente $\mathrm{N}$-substituídas.

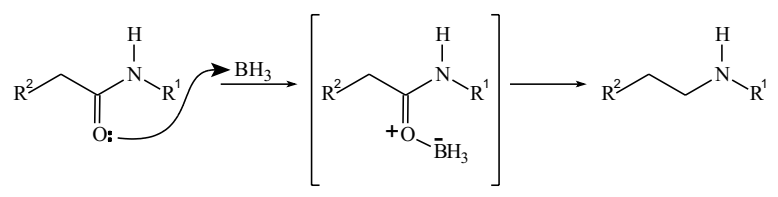

\section{REATIVIDADE DAS AMIDAS EM REDUÇÕES POR BORANOS}

Para diferentes grupos funcionais, a reatividade de redutores eletrofílicos é influenciada significativamente pela estrutura dos substituintes nos reagentes e apresenta-se relacionada com o poder de complexação entre os heteroátomos e o boro ${ }^{38,39}$. De um modo geral, para a redução com borano em THF, tem-se a seguinte ordem de reatividade: ácidos carboxílicos $>$ olefinas $>$ cetonas $>$ nitrilas $>$ epóxidos > amidas $>$ ésteres $>$ haletos de acila. Além disso, para nitro-compostos, sulfonas, sulfetos, sulfóxidos, dissulfetos, tosilatos, haletos de alquila e vários outros grupos funcionais, o borano é essencialmente inerte ${ }^{40-42}$.

Segundo a literatura, a deslocalização eletrônica sobre o grupo amido proporciona uma densidade de carga positiva sobre o nitrogênio e negativa sobre o oxigênio ${ }^{43}$. Entretanto, alguns resultados sugerem também uma alta densidade eletrônica sobre o nitrogênio ${ }^{44}$. Desta forma, a deficiência eletrônica dos redutores eletrofílicos favorece a interação com os heteroátomos do grupo amido, podendo ocorrer pelo oxigênio (Equação 3), mais favorecida termodinamicamente ${ }^{45}$, ou pelo nitrogênio (Equação 4). Estas interações são propostas considerando a similaridade destes adutos com aqueles formados a partir de trifluoreto de boro com aldeídos ou cetonas e de boranos com aminas terciárias, respectivamente ${ }^{46}$.

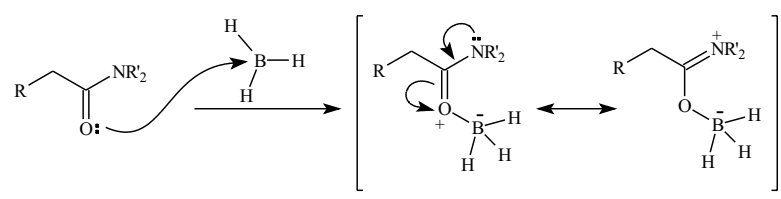

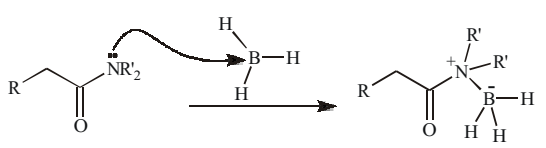

Considerando que amidas, ésteres e ácidos carboxílicos apresentam deslocalização eletrônica envolvendo seus heteroátomos, podem ser propostas algumas similaridades nos mecanismos de redução desses grupos funcionais. Em relação aos ácidos carboxílicos, foi verificado que, apesar de serem facilmente reduzidos, seus sais formam adutos com borano sem, entretanto, sofrerem reduções posteriores (Equação 5$)^{47}$. Isto sugere que a presença de hidrogênios ativos é importante no mecanismo dessas reduções eletrofílicas ${ }^{48}$.

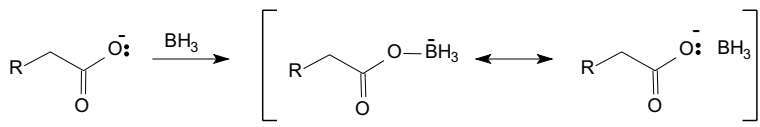

Por outro lado, a reação de ácidos carboxílicos com baixas concentrações relativas de borano forma carboxiboranos estáveis (Equação 6). Por isto, a literatura sugere que a etapa determinante da redução de ácidos carboxílicos seja a de formação do intermediário triaciloxiborano, com evolução de hidrogênio ${ }^{49}$. Este intermediário comporta-se essencialmente como um anidrido misto ativado pela natureza eletronegativa do átomo de boro trivalente ${ }^{50}$, apresentando o carbono carboxílico mais susceptível à redução do que aquele de carbonilas em aldeídos ou cetonas. A facilidade da redução de ácidos carboxílicos tem sido atribuída também à formação intermediária de boratos de trialquila, oriundos do desproporcionamento dos triaciloxiboranos. Provavelmente, estes boratos comportam-se como catalisadores neste tipo de reação ${ }^{51}$.

$\prod_{\mathrm{O}}^{\mathrm{R}} \underset{-\mathrm{H}_{2}}{\stackrel{\mathrm{BH}}{\longrightarrow}}[\mathrm{THF}$

Nas reduções de ácidos carboxílicos por borano tem sido proposta também a formação de triacetoxiboro-hidretos como intermediários (Equação 7) ${ }^{52}$. Entretanto, os efeitos estéricos e indutivos dos três grupos acetoxila tornam este tipo de intermediário desfavorecido termodinamicamente e sugerem um envolvimento pouco significativo de triacetoxiboro-hidretos no mecanismo de redução de ácidos carboxílicos por boranos.<smiles></smiles>

Os ésteres são menos reativos que as amidas nas reduções por boranos. Dois fatores podem ser considerados sobre este fato: primeiro, a possibilidade de boranos presentes no meio adicionarem-se ao oxigênio não carbonílico, competindo com a adição ao oxigênio carbonílico e, segundo, diferentemente dos ácidos carboxílicos e amidas, a menor deslocalização eletrônica sobre ésteres pode 
desfavorecer a formação do aduto e, conseqüentemente, dificultar a

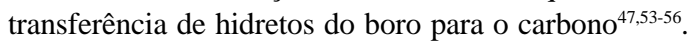

Pela maior reatividade de amidas em relação a ésteres, elas podem ser reduzidas seletivamente por borano em compostos contendo ambos os grupos funcionais. Entretanto, dependendo de fatores estruturais, os grupos carboalcoxi e amido podem ser reduzidos concomitantemente. Neste caso, a redução é favorecida pela formação de um intermediário cíclico devido às interações do boro ligado ao nitrogênio com o oxigênio carbonílico do grupo carboalcoxi, aumentando conseqüentemente o caráter eletrofílico do carbono carbonílico (Equação 8) ${ }^{57}$. Quando tal interação torna-se menos favorecida estruturalmente, é verificada uma menor reatividade relativa do éster (Equação 9). Entretanto, em ambos os casos, verifica-se a maior seletividade de amidas em relação aos ésteres nas reduções por boranos, conforme a ordem de reatividade para os grupos funcionais apresentada anteriormente.

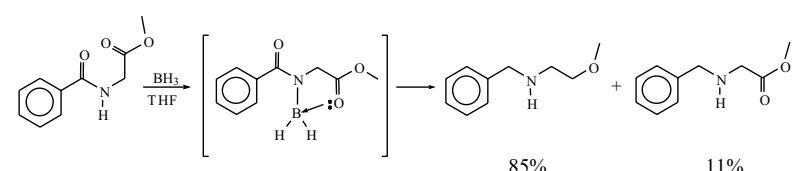
$85 \%$ $11 \%$<smiles>CCOC(=O)C(=O)NCC#[C+]COC(=O)C[18O]CCOCCN</smiles>

Alguns estudos foram relatados sobre a influência de efeitos estéricos e eletrônicos nas reduções por boranos de diferentes compostos carbonílicos ${ }^{58,59}$. A introdução de substituintes alquilas em posição alfa à carbonila aumenta a reatividade de redução de amidas e não influencia a velocidade de redução de ácidos carboxílicos ${ }^{39}$. Mesmo ácidos carboxílicos estericamente impedidos têm sido reduzidos facilmente (Equação 10). Por outro lado, a introdução de grupos eletronegativos, tal como halogênio, no carbono alfa-carbonílico diminui a reatividade em reduções empregando boranos, conforme verificado para redução dos ácidos dimetilpropanóico e tricloroacético (Equações 11 e 12, respectivamente), nas mesmas condições e tempo de reação ${ }^{59}$.
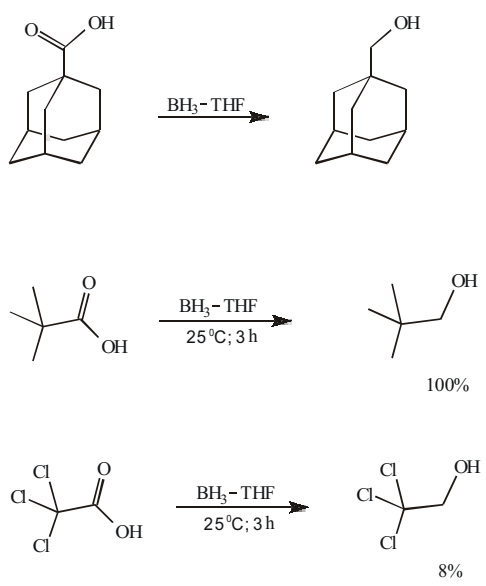

Apesar de não serem semelhantes estruturalmente em relação às amidas, as olefinas evidenciam a dependência marcante do efeito estérico nas reduções por boranos, influenciando significativamente o mecanismo de reação ${ }^{60}$. Assim, em olefinas dissubstituídas, a redução procede consumindo completamente todos os hidretos ativos do borano (Equação 13). Entretanto, com olefinas trissubstituídas, a temperatura ambiente, a reação consome somente $2 / 3$ dos hidretos, obtendo-se dialquilboranos ou dímeros correspondentes como produtos (Equação 14). Finalmente, a reação com olefinas tetrassubstituídas fornece normalmente apenas o produto monoalquilborano (Equação 15) ${ }^{61}$. Assim, dentre os produtos hidroborados, podem ser formados vinilboranos, alquenilboranos, arilboranos, alilboranos e outros boranos substituídos na forma tanto monomérica quanto dimérica ${ }^{62}$.<smiles>[R]C=CC(C)C([R])CN([R])C([R])C([R])C[Y]</smiles>

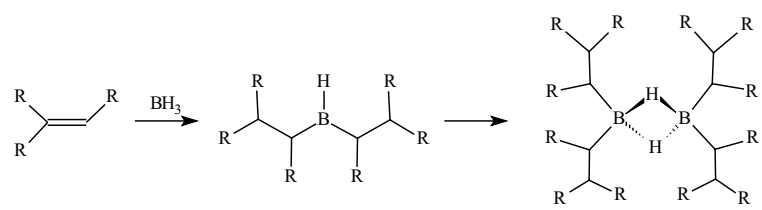<smiles>[R]C([2H])=C([R])[2H]</smiles>

Em relação à substituição no nitrogênio do grupo amido, observa-se um comportamento distinto ao da substituição no carbono $\alpha$ carbonílico $^{35,36}$. Assim, amidas contendo grupos N-substituintes ramificados ou não ramificados são reduzidas facilmente por boranos $^{63}$. Por outro lado, efeitos eletrônicos podem influenciar a reatividade pois observa-se maior reatividade de amidas aromáticas em relação às alifáticas, as quais apresentam menores deslocalizações eletrônicas envolvendo o grupo amídico ${ }^{64}$. Mesmo em condições nucleofílicas, quando o borano é gerado in situ (a partir de $\mathrm{LiBH}_{4}$ diglima-MeOH), $\mathrm{N}$-arilamidas secundárias tornam-se também mais reativas do que as $\mathrm{N}$-alquil-amidas correspondentes.

As estruturas contendo grupos amido com diferentes graus de $\mathrm{N}$-substituição apresentam baixa seletividade em reduções ${ }^{65}$. No entanto, amidas terciárias sofrem reduções por boranos em condições mais brandas do que amidas primárias e secundárias ${ }^{66}$. Nas reduções empregando diborano em $\mathrm{THF}$ a $0{ }^{\circ} \mathrm{C}$, amidas terciárias são facilmente reduzidas e as amidas primárias são lentamente reduzidas, exibindo $50 \%$ de redução após $48 \mathrm{~h}^{67,68}$. De um modo geral, verificase que a reatividade diminui na ordem ${ }^{35,69,70}$ : terciárias $>$ secundárias > primárias. Esta ordem está de acordo com a diminuição da densidade eletrônica sobre o nitrogênio, devido aos efeitos indutivos de grupos alquila.

A maior reatividade de amidas terciárias pode ser evidenciada também quando se empregam complexos borano:selênio $\left(\mathrm{BrCH}_{2} \mathrm{CH}_{2}\right)_{2} \mathrm{Se}: \mathrm{BH}_{3}$, em que amidas terciárias são reduzidas às aminas correspondentes, comportando-se diferentemente das amidas com menor grau de $\mathrm{N}$-substituição, as quais não são reativas ${ }^{71}$. Em alguns casos, essa ordem pode ser alterada, verificando-se maior reatividade de amidas secundárias em relação às amidas primárias ${ }^{72}$.

\section{REATIVIDADE DOS BORANOS}

Em reações envolvendo boranos substituídos, pode-se observar que a modificação do ambiente estérico e eletrônico no boro influencia sua reatividade ${ }^{73}$. Isto é acentuado com o aumento do volume 
do redutor ${ }^{74}$, proporcionando um maior grau de especificidade nas reduções. Assim, diferente de amidas primárias, as amidas secundárias e terciárias são relativamente inertes quando se emprega catecolborano, mesmo na presença de quantidades catalíticas de sais de irídio (Equação 16) ${ }^{75}$. Comportamento análogo é observado para ésteres pois, apesar de borano reduzir lentamente compostos deste tipo, a introdução de grupos B-alquilsubstituintes diminui a reatividade, podendo os ésteres tornarem-se inertes, dependendo do dialquilborano empregado ${ }^{76}$.

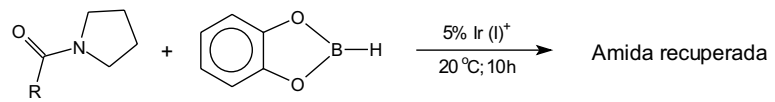

No caso do 9-borabiciclo-[3.3.1]nonano (9-BBN), a cinética de sua reação com vários grupos funcionais indica um desfavorecimento para dissociação do dímero semelhante ao DB (Equação 17), permitindo distinguir essa etapa como a determinante da velocidade de redução. Desta forma, as etapas posteriores, envolvendo a reação do grupo funcional com o monômero do 9-BBN, são consideradas como mais rápidas ${ }^{30}$.

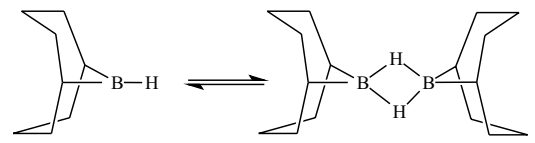

Apesar de ser menos estável do que a ligação B-N77, a ligação boro-halogênio, quando presente nos boranos, aumenta relativamente a acidez do redutor sem, entretanto, influenciar significativamente sua reatividade. $\mathrm{O}$ dicloroborano é um agente redutor mais brando do que os aciloxiboranos; reduz seletivamente azidas, não reduzindo, contudo, muitos substratos como haletos de acila, ésteres, nitrilas e nitrocompostos ${ }^{78}$.

Complexos aminodi-haloboranos do tipo $\mathrm{BHI}_{2}: \mathrm{NR}_{3}$ reduzem facilmente amidas terciárias, mas não reduzem apreciavelmente amidas secundárias ${ }^{79}$. A complexação deste redutor com álcoois (Equação 18) e ácidos carboxílicos (Equação 19) proporciona evolução de hidrogênio e formação de produtos com ligação B-O. Isto sugere um comportamento semelhante na formação de ligações boro-nitrogênio ou borooxigênio para as amidas que levam à evolução de hidrogênio.

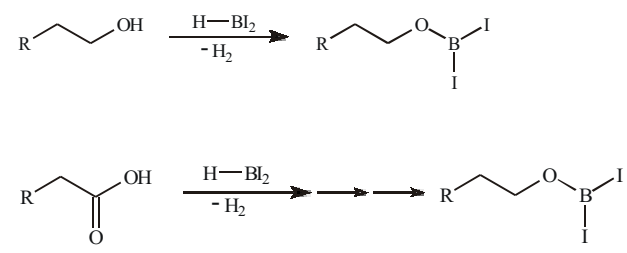

Considerando que o borano apresenta-se normalmente na forma dimérica ou complexado, a interação do borano com o grupo amido é influenciada pelo poder de complexação do solvente empregado nas reduções ${ }^{70,80}$. Em hidroboração de alquenos, verifica-se que a velocidade de redução é maior quando é empregado THF em relação a pentano, diclorometano ou éter etílico. Semelhantemente, o efeito do solvente nas reduções de ésteres mostra que a reação é mais rápida com DB, mais lenta com aduto borano-THF e mais lenta ainda com aduto borano-dimetilsulfeto $\left(\mathrm{BH}_{3}-\mathrm{DMS}\right)^{39}$. A menor velocidade de redução empregando DMS pode ser atribuída ao baixo ponto de ebulição do DMS, diminuindo conseqüentemente a temperatura de refluxo da reação.
Semelhante ao observado para ésteres, nas reduções de amidas, os poderes redutores do borano em THF e em diclorometano são próximos. Em muitas reações, a solução com DMS é menos reativa. Entretanto, o aduto borano-DMS apresenta também reatividade aumentada, comparável ao do DB não complexado, quando o solvente é removido da mistura de reação. Já o aduto amina-borano, por ser mais estável do que os demais, apresenta-se pouco dissociado, sendo, desta forma, inerte para reação de transferência de hidreto ${ }^{24,68}$.

Um outro fator muito importante sobre a reatividade dos boranos é a temperatura de reação pois está associada também à estabilidade do aduto borano-solvente. Por isso, as reduções de amidas secundárias por borano tornam-se relativamente mais rápidas sob refluxo ${ }^{81}$.

\section{ETAPAS DE REDUÇÃO}

De um modo geral, a redução de amidas por boranos passa por etapas específicas de consumo de hidretos do redutor para formação das aminas correspondentes. A seqüência das etapas depende da estrutura das amidas, apresentando normalmente evolução de hidrogênio (para amidas primárias e secundárias), complexação, formação do intermediário tetraédrico, hidrogenólise da ligação $\mathrm{C}-\mathrm{O}$ e formação do aduto amina-borano (para amidas secundárias e terciárias) ${ }^{39,82}$, conforme Figura 2.

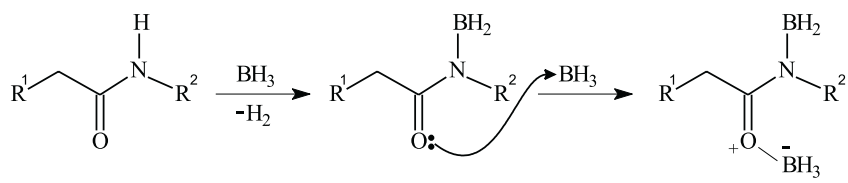

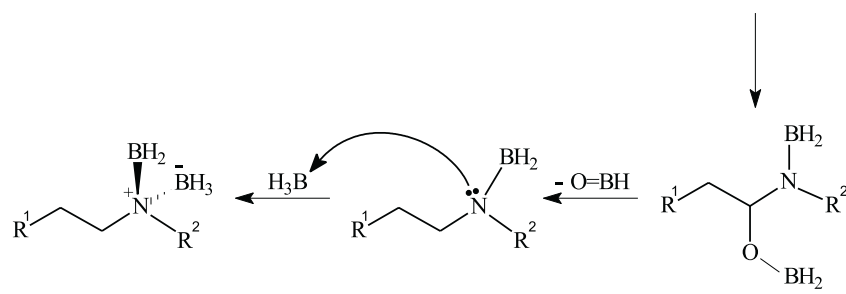

Figura 2. Seqüência de etapas observadas para redução de amidas secundárias empregando borano

\section{Evolução de hidrogênio}

Na redução por boranos, as amidas terciárias consumem rapidamente dois equivalentes de hidreto na hidrogenólise total da ligação $\mathrm{C}=\mathrm{O}$, mesmo sob baixas temperaturas, sem ocorrer evolução de hidrogênio. Considerando que essas amidas são mais reativas em relação às primárias e secundárias ${ }^{64}$, pode-se propor que a evolução de hidrogênio faz diminuir a reatividade de redução. De fato, o intermediário formado a partir da evolução de hidrogênio em amidas primárias e secundárias apresenta propriedades distintas em relação aos intermediários oriundos de redução de amidas terciárias ${ }^{83}$. Isto está de acordo com o verificado também para ácidos carboxílicos que sofrem eficientemente reduções por boranos, diferente de íons carboxilato que não apresentam evolução de hidrogênio e são inertes $^{47,48}$.

No caso de amidas primárias, devido à presença de dois hidrogênios ativos, tem sido verificada uma etapa inicial de consumo de dois equivalentes de hidreto do redutor, com evolução de hidrogênio molecular (Equação 20) 35,36,39.

Quando se emprega borano como redutor, todos os seus três hidretos são consumidos na evolução de hidrogênio. Para amidas 
primárias tem sido proposta a formação de um intermediário do tipo $[R C(=O) N]_{3} B_{2}$ (Equação 21), que é normalmente muito estável ${ }^{84}$.

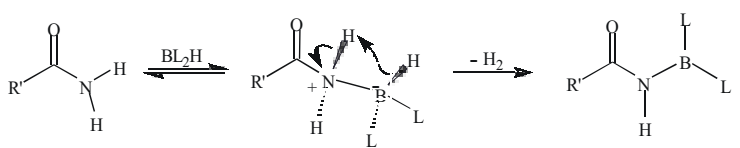<smiles>[R]C(=O)N1C2N(C([R])=O)C1N2C([R])=O</smiles>

Além disto, pode-se propor também a formação de estruturas cíclicas mais simples contendo menor quantidade relativa de grupos amido (Equação 22) ${ }^{85}$ ou, ainda, a formação de estruturas apresentando anéis fundidos (Equação 23) ${ }^{73}$.<smiles>[R]C(=O)N1BN(C([R])=O)B1</smiles><smiles>[R]C(=O)N1BN2C([R])=[PH][BH-]1N2CCCC</smiles>

Em muitos casos, apesar de ser inicialmente muito rápida, tem sido verificada também que essa evolução de hidrogênio termina bem antes de dois equivalentes de hidreto serem consumidos, variando normalmente entre 1,10 e 1,40 equivalentes. Posteriormente, o consumo restante de hidreto para evolução de hidrogênio torna-se muito lento ${ }^{86}$. Apesar de os complexos contendo ligações B-N serem moderadamente estáveis, mesmo na presença de oxigênio molecular e umidade ${ }^{87,88}$, a evolução incompleta de hidrogênio pode ser atribuída também ao ataque competitivo do redutor ao oxigênio ${ }^{35,36}$, conforme Equação 24. Nesse caso, a evolução do segundo equivalente de hidrogênio é dependente de efeitos estéricos que influenciam a interação entre o nitrogênio e a segunda molécula de borano.

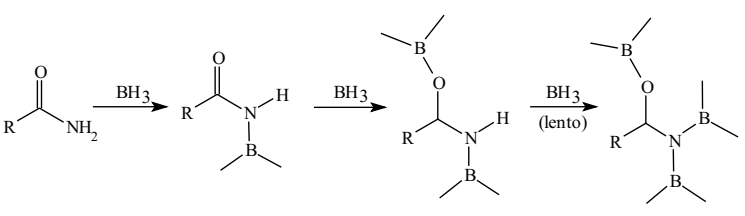

Por outro lado, na reação entre amidas primárias e disiamilborano (Equação 25), verifica-se evolução lenta de hidrogênio, não ocorrendo redução da carbonila ${ }^{32}$. Isso pode indicar que os fatores estéricos relacionados com o grau de B-substituição não são determinantes na etapa de evolução de hidrogênio. Entretanto, o grau de B-substituição desfavorece a interação do oxigênio com outra molécula de disiamilborano, conforme o impedimento estérico sobre o oxigênio mostrado na Figura 3.

Na redução de amidas secundárias, semelhantemente à formação de álcoois a partir de ácidos carboxílicos ${ }^{89}$, verifica-se a evolu- ção de hidrogênio durante a primeira etapa de reação (Equação 26). Esta evolução de hidrogênio não é a etapa de reação mais favorecida cineticamente pois, em muitos casos, têm sido verificadas simultaneamente a evolução de hidrogênio e a formação de aduto aminaborano $^{39}$. Quando o redutor é o diborano, a estrutura do grupo Nsubstituinte não influencia significativamente a velocidade da redução $0^{81}$.<smiles>[R]C(=O)N(B(C(C)C(C)C)C(C)C(C)C)B(C(C)C(C)C)C(C(C)C)C(C)C</smiles>

Figura 3. Geometria otimizada para o produto da redução entre acetamida e disiamilborano, sendo $H$ (amarelo), $C$ (cinza), $O$ (vermelho), $B$ (laranja) $e$ $N$ (azul). Cálculo empregando o método $A M 1^{7}$

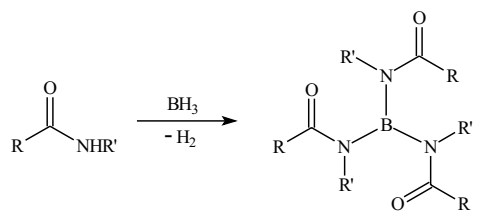

Entretanto, apesar do maior caráter ácido de amidas secundárias em relação às aminas correspondentes ${ }^{90}$, a evolução de hidrogênio na primeira etapa de redução destas amidas não deve ser favorecida pois, por analogia, tal evolução no caso de aminas ocorre apenas em condições drásticas (Equação 27) ${ }^{91,92}$. Estes resultados podem explicar o consumo parcial de hidrogênios ativos do borano na evolução de hidrogênio.

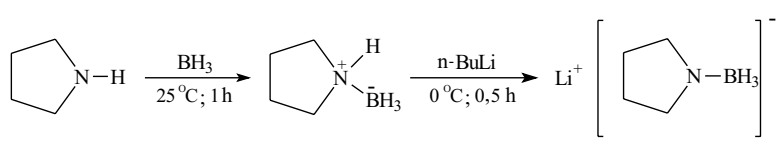

Além do consumo de hidrogênios ligados ao nitrogênio de amidas, deve-se considerar que a evolução de hidrogênio pode ser atribuída também ao processo de enolização, sendo, neste caso, denominada de enolboração. Em ácidos carboxílicos, a enolboração requer dois equivalentes de borano, sendo um equivalente para consumir o hidrogênio ácido e o outro na complexação com o oxigênio carbonílico (Equação 28, onde $\mathrm{Chx}=$ ciclo-hexila) ${ }^{93}$. Entretanto, no caso de amidas, a evolução de hidrogênio não tem sido atribuída à possibilidade de enolboração $0^{94}$. Este tipo de enolização tem sido verificado somente para reações envolvendo amidas terciárias aromáti- 
cas ou alifáticas, empregando dialquilboranos como redutores e na presença de aminas terciárias impedidas estericamente (Equação 29) ${ }^{95}$. De um modo geral, a enolboração de amidas terciárias é influenciada pela temperatura de reação, natureza do solvente e pela estrutura da amida, do borano e da amina terciária empregada como base ${ }^{63,96}$.

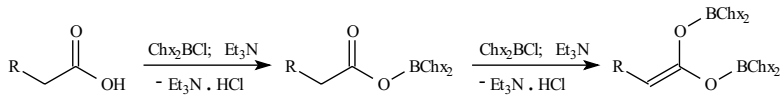

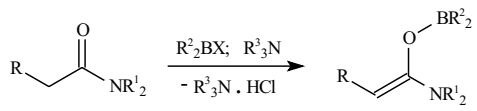

Considerando a facilidade da redução de alquenos, a hidroboração dos intermediários de enolboração poderia ocorrer em redução de amidas quando as condições de reação favorecem este tautomerismo. Caso contrário, para amidas aromáticas ou alfa-tri-substituídas, seria esperado outro mecanismo de reação.

\section{Complexação}

Em princípio, tanto o oxigênio quanto o nitrogênio são os sítios nucleofílicos das amidas que permitem a sua complexação com boranos ${ }^{97}$. Apesar de resultados descritos na literatura indicarem normalmente maior densidade eletrônica sobre o oxigênio das amidas, estudos envolvendo cálculos de isomerização do tipo ceto-enol de amidas indicam maior densidade de carga eletrônica sobre o nitrogênio ${ }^{98}$. Além disto, após evolução de hidrogênio, a complexação da amida com o borano é influenciada por fatores eletrônicos. Neste caso, o poder nucleofílico do nitrogênio torna-se relativamente menor pois a sua densidade eletrônica diminui, distribuindo-se com deslocalização para o boro (Equação 30) que, por sua vez, pode favorecer retro-doação, aumentando a densidade de elétrons $\pi$ no nitrogênio ${ }^{99}$, com conseqüente estabilização. Por isso, esta ligação torna-se mais favorecida ${ }^{100}$, sugerindo que a complexação inicial ocorra pelo nitrogênio do grupo amido. Entretanto, vários resultados experimentais evidenciam a complexação inicial do borano com o oxigênio. No caso de fosfinamidas, tem sido proposto que suas reduções envolvem inicialmente a coordenação do oxigênio ao borano ${ }^{101}$.

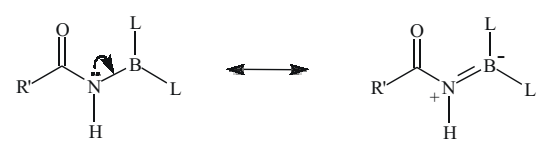

Enolboração de amidas ocorre pela complexação inicial do borano com o oxigênio ${ }^{102}$, proporcionando a formação de ligação covalente B-O, conforme proposto para amidas terciárias (Equação 29). Considerando a possibilidade de enolização verificada nas reações entre cetonas e boranos trissubstituídos ${ }^{61,103}$, o intermediário análogo da reação de amidas pode ser mais estável devido ao deslocamento dos elétrons não-ligantes do nitrogênio. Desta forma, efeitos estéricos e eletrônicos nos complexos borano-amidas primárias justificam a maior reatividade das amidas terciárias em enolboração. Apesar disto, não justificam a menor reatividade da redução de amidas em relação a cetonas, sugerindo que a enolboração, caso ocorra, não seja a etapa determinante na cinética de reação.

Uma outra evidência da maior ativação relativa do oxigênio para complexação é verificada em hidroborações catalíticas que ocorrem lentamente via adição oxidativa envolvendo o borano e o catalisador ácido de Lewis $\left(\mathrm{E}^{+}\right)$, seguida pela eliminação redutiva de alquil- ou dialquenilboranos ${ }^{104}$. O catalisador coordena-se ao oxigênio, ativan- do o substrato para ataques nucleofílicos, principalmente quando se emprega boro-hidreto de sódio ${ }^{105}$.

No caso de redutores eletrofílicos, a regiosseletividade nas reduções de amidas pelo favorecimento da coordenação de boranos com o oxigênio pode ser corroborado pelos resultados obtidos quando se empregam ácidos de Lewis. Estes catalisadores são eficientes em reduções de cetonas e de outros compostos carbonilados ${ }^{106,107}$, favorecendo mecanismos intramoleculares altamente seletivos. Pelas suas propriedades químicas, estes catalisadores devem favorecer também complexação pelo oxigênio, ativando-o e direcionando-o para ataques de hidretos (Equação 31) ${ }^{108}$. Entretanto, os mesmos catalisadores empregados em reduções de cetonas podem não ser ativos para reduções de amidas, sugerindo outros intermediários nas reações.

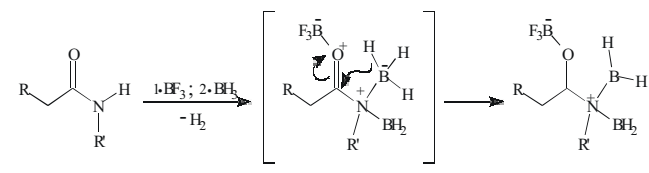

No caso de amidas secundárias, esta complexação inicial não é a etapa determinante da velocidade de redução pois estas amidas são mais facilmente reduzidas do que os carbamatos, conforme Equação $32^{109}$. Caso contrário, pelas maiores densidades eletrônicas tanto no nitrogênio quanto no oxigênio do grupo carbamato, seria esperada sua maior reatividade em complexação do que para amidas secundárias.

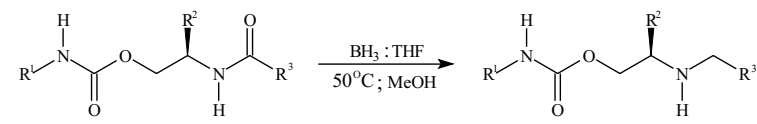

De um modo geral, vários fatores influenciam a reatividade em ataques eletrofílicos do borano ao oxigênio, sendo dependente das condições estéricas tanto da amida ${ }^{110}$ quanto do borano ${ }^{111}$. Além disso, a acidez dos boranos é também muito importante na determinação dos produtos e seletividade da redução envolvendo compostos carbonílicos ${ }^{112}$. Assim, por estes resultados, pode-se propor que, caso haja evolução de hidrogênio, a etapa seguinte na redução envolva preferencialmente a complexação do oxigênio com o borano.

\section{Intermediário tetraédrico}

Da mesma forma verificada para redutores nucleofílicos, a reação de amidas com redutores eletrofílicos passa também por um intermediário tetraédrico. Exceto em situações em que a energia de dissociação do redutor na forma dimérica é maior (Equação 33; onde $\mathrm{L}=$ substituinte qualquer), a etapa determinante da velocidade de redução é atribuída geralmente à formação daquele intermediário ${ }^{113}$.

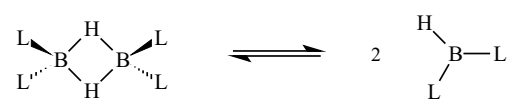

A formação do intermediário tetraédrico ocorre em duas etapas, apresentando inicialmente a ativação do oxigênio e, posteriormente, ataque por hidreto ao carbono do grupo amido (Equação 34$)^{35}$. A ativação do oxigênio é favorecida pela interação com o próprio redutor ou catalisadores e solventes ácidos, formando um intermediário estabilizado por fatores eletrônicos ${ }^{114,115}$. Apesar de amidas protonadas apresentarem $\mathrm{pK}_{\mathrm{a}}$ entre 0,0 e 2,0, tanto em água quanto em outros solventes tais como sulfóxido de dimetila ${ }^{116}$, pode-se propor uma 
razoável concentração de amidas complexadas em meios ácidos, sendo suficiente para ocorrer a redução.

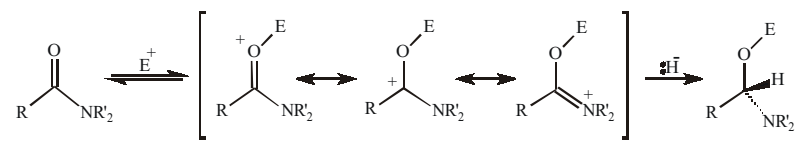

Para a formação do intermediário, a adição nucleofílica de hidretos ao carbono do grupo amido é uma etapa fundamental. Esta adição pode ocorrer por via intermolecular (Equação 35), conforme proposição para redução de amidas terciárias por aminoboro-hidreto de lítio $\left(\mathrm{LiBH}_{3} \mathrm{NH}_{2}\right)^{63}$. Entretanto, considerando que a formação do intermediário tetraédrico a partir de cetonas seja mecanisticamente semelhante à de amidas, o alto grau de enanciosseletividade na redução de cetonas pró-quirais ${ }^{111,117}$, de diaril-1,2-dionas ${ }^{118}$ e a utilização de fosfanamida ${ }^{119}$ ou outras condições catalíticas ${ }^{106}$ sugerem que a adição de hidretos ao carbono funcionalizado seja intramolecular.<smiles>[Y6]C([Y])O[Y]([H])([H])[3H]</smiles>

Além de ter entropia favorável, a adição intramolecular de hidretos apresenta um fator de contribuição adicional. Trata-se da estabilização eletrostática que pode ocorrer entre o boro carregado negativamente e o nitrogênio carregado positivamente (Figura 4). Neste caso, $o$ ataque intramolecular pode ser favorecido pela re-hibridização dos
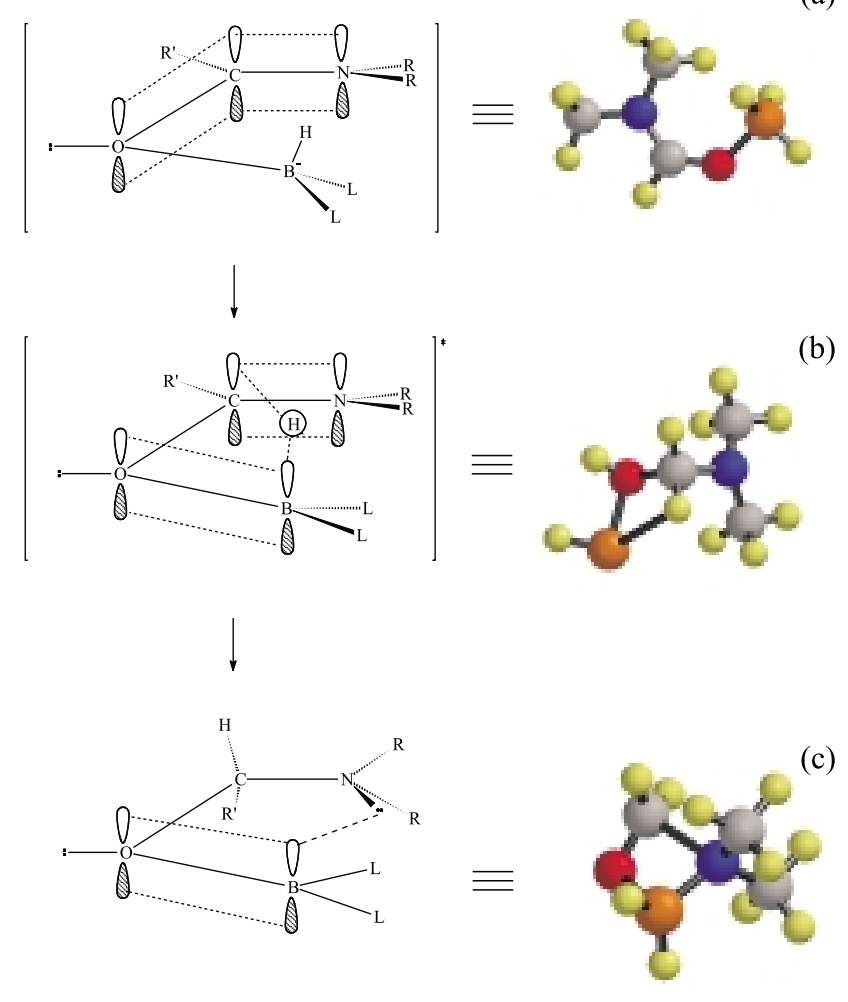

Figura 4. Etapas da transferência de hidretos, (a) e (b), na formação do intermediário tetraédrico (c) durante redução de amidas por boranos, sendo $H$ (amarelo), C (cinza), $O$ (vermelho), $B$ (laranja) e $N$ (azul). Cálculo empregando o método $A M 1^{7}$ átomos do grupo amido, proporcionando maior aproximação entre o nitrogênio e o boro ligado ao oxigênio, com transferência concomitante de hidreto.

De acordo com esta proposta, o valor calculado para a distância interatômica entre nitrogênio e boro após adição de hidreto (intermediário re-hibridizado, Figura 4c) é $2,91 \AA^{7}$, sendo maior do que as ligações covalentes $\mathrm{N}-\mathrm{B}$ com comprimentos próximos de $1,58 \AA^{120}$. Estes resultados sugerem apenas uma interação relativamente fraca entre boro e nitrogênio no intermediário, podendo ser, entretanto, importante na transferência de hidretos durante a redução de amidas por borano. Além disso, o ataque de hidretos pode ser influenciado por fatores estéricos de forma semelhante à verificada para cetonas e cetoximas quando se empregam ácidos de Lewis como catalisadores ${ }^{121}$.

Levando em consideração uma proposta para o ataque intramolecular de hidreto ao carbono do benzaldeído na redução por alpino-borano ${ }^{122}$, a redução de amidas pode envolver também estados de transição tipo "ciclo-hexanóide" na conformação preferencialmente bote (Equação 36).

$$
\longrightarrow \longrightarrow \longrightarrow
$$

Por outro lado, a interação de intermediários em etapas diferentes de redução pode explicar outros estados de transição envolvendo ataques intermoleculares de hidretos para formação do intermediário tetraédrico (Equação 37) ${ }^{79,123}$. De qualquer forma, os estados de transição apresentados nas Equações 36 e 37 podem sugerir diferenças de mecanismo e, conseqüentemente, de reatividade em reduções de amidas primárias, secundárias e terciárias devidas às alterações estruturais dos grupos B-substituintes.

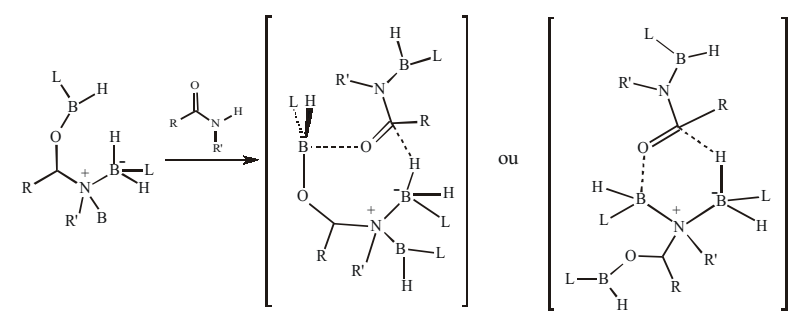

\section{Redução do intermediário tetraédrico}

As reduções de amidas levam normalmente à formação seletiva de aminas correspondentes, empregando tanto redutores nucleofílicos ${ }^{124}$ quanto eletrofílicos ${ }^{90}$. Apesar de apresentarem propriedades químicas e reatividades bem distintas, os mecanismos de redução podem ter etapas semelhantes quando se empregam estes dois tipos de redutores. Desta forma, mesmo em reduções por boranos, pode ser proposta também a formação intermediária de estruturas contendo grupos boro-hidreto substituídos, sendo provavelmente estes os redutores efetivos da reação. Consequientemente, os reagentes e intermediários podem ser reduzidos por hidretos ativos oriundos de boranos ou boro-hidretos tanto mono- quanto di-substituídos presentes no meio de reação ${ }^{125,126}$, levando à formação dos produtos correspondentes ${ }^{127}$. Além disso, considerando a importância do intermediário tetraédrico na redução de amidas, a obtenção de aminas 
pode ser explicada por várias propostas mecanísticas a partir deste intermediário.

As evidências do envolvimento do nitrogênio na hidrogenólise total da ligação $\mathrm{C}=\mathrm{O}$ em amidas podem ser ressaltadas a partir da análise dos resultados da reação de cetonas e álcoois com boranos $^{114,116}$. Normalmente, cetonas são reduzidas a álcoois, ocorrendo inicialmente interação entre boro e oxigênio (Equação 38) ${ }^{102}$. Os intermediários alcoxiboranos formados são relativamente estáveis, não favorecendo posteriormente a hidrogenólise da ligação $\mathrm{C}-$ O. O poder nucleofílico proposto para estes intermediários alcoxiboro-hidretos na liberação de hidretos justifica determinados produtos que têm sido verificados em reduções ${ }^{119}$.

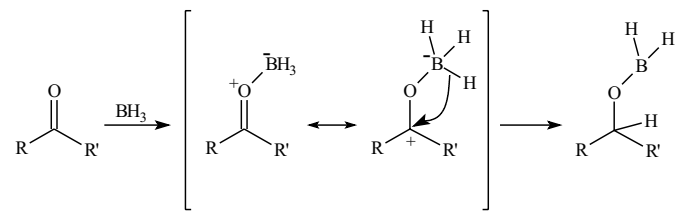

Por sua vez, os álcoois ao reagirem com diborano, liberam hidrogênio, não se verificando a ocorrência de redução a hidrocarbonetos saturados (Equação 39). Entretanto, de forma semelhante ao esperado para reduções de amidas, o envolvimento de elétrons "p" ou " $n$ " adjacentes à carbonila em cetonas ou álcoois proporciona a hidrogenólise total desta ligação. Isto pode explicar o porquê da formação de difenilmetano, em vez do álcool correspondente, com $84 \%$ de rendimento, a partir da redução de difenilcetona por dimetilaminoborano ${ }^{128}$.

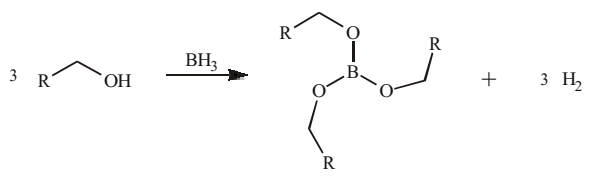

Uma outra evidência do envolvimento do nitrogênio na hidrogenólise total da ligação $\mathrm{C}=\mathrm{O}$ em reduções de amidas pode ser verificada na reação de boranos com amino-álcoois vicinais. Nessa reação ocorre apenas evolução de hidrogênio (Equação 40), sem hidrogenólise posterior ${ }^{129}$, sugerindo uma maior estabilização do estado de transição da reação envolvendo o amino-álcool vicinal, do que o correspondente para os intermediários tetraédricos que são amino-álcoois geminais.<smiles>NC([AlH2])C(O)CO</smiles><smiles>OCC1OBNC1[AlH2]</smiles>

Apesar de nitrilas serem intermediárias ou produtos de reação de amidas primárias com redutores nucleofílicos $\left(\mathrm{NaBH}_{4}\right.$ ou $\mathrm{LiBH}_{4} \mathrm{em}$ diglima $)^{28,36}$, a formação de aminas pela redução por boranos pode ser proposta por hidrogenólise da ligação $\mathrm{C}-\mathrm{O}$ do intermediário tetraédrico, via intermediário cátion imino que é estabilizado por deslocalização eletrônica envolvendo o nitrogênio (Equação 41). Na formação deste intermediário ${ }^{64}$, principalmente para amidas terciárias ${ }^{63,130}$, a sua deficiência eletrônica desfavorece interações com ácidos de Lewis. Desta forma, conforme verificado em redução de amidas secundárias por hidrozirconização $0^{95}$, pode-se propor que a formação da amina, a partir do cátion imino, ocorre por ataque nucleofílico de hidretos, levando rapidamente à formação da amina correspondente. Este ataque ao cátion imino pode ser controlado estericamente, conforme verificado em reduções enanciosseletivas de iminas por boranos ${ }^{131}$.

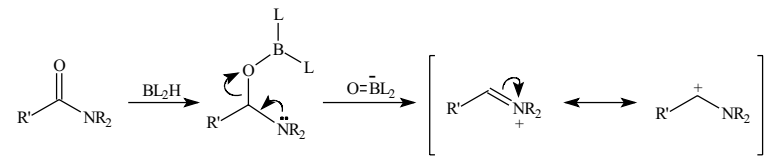

Da mesma forma, em aminações redutivas de aldeídos (Equação 42), apesar de a literatura indicar que o cátion imino sofre redução à amina correspondente, tem sido sugerida uma redução direta da carbinolamina como possível caminho de reação ${ }^{132}$. No caso de aminações redutivas de cetonas pouco reativas, a presença de imina nos produtos tem sido verificada por análise de Cromatografia Gasosa acoplada à Espectrometria de Massas (CG-EM) da mistura de reação. Além disso, é possível que estas reações procedam via formação inicial de intermediário enamina em vez de imina, explicando a baixa reatividade em aminações redutivas de aldeídos aromáticos que não podem formar enaminas ${ }^{125}$. Finalmente, estas reações envolvendo aldeídos e cetonas são realizadas mais eficientemente com redutores nucleofílicos boro-hidretos pois, quando são empregados redutores eletrofílicos tais como boranos, os rendimentos dos produtos de aminação redutiva são baixos.

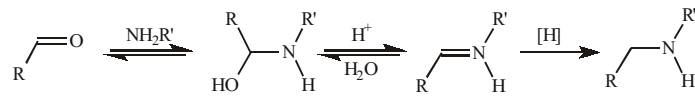

Da mesma forma, verifica-se a ocorrência de hidrogenólise total da ligação carbono-nitrogênio em imino-compostos quando se utiliza DB como redutor ${ }^{133}$, principalmente em estruturas contendo duas ligações C-N geminais (Equação 43) ${ }^{134}$. Além disto, apesar da formação de aminas terciárias a partir de aminas secundárias e iminas ${ }^{135}$, análises por CG-EM não registraram a presença destes produtos competitivos em reduções de amidas secundárias por boranos ${ }^{136}$. Assim, por estes resultados, pode-se propor que, no caso de amidas, a redução não deve proceder via formação de cátion imino ${ }^{137,138}$.

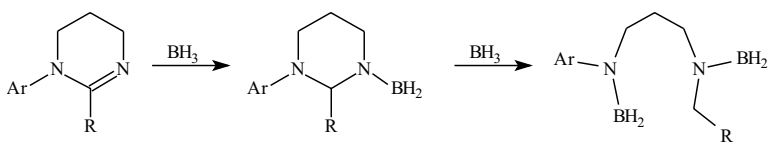

Considerando que as amidas e boranos contendo grupos substituintes pouco volumosos não apresentam restrições estéricas significativas para interações intramoleculares de nitrogênio e borano ligado ao oxigênio (Figura 3), pode ser proposta que a hidrogenólise da ligação carbono-oxigênio no intermediário tetraédrico ocorra por ataque nucleofílico intramolecular de hidretos (Equação 44). Esse intermediário pode ser hidrolisado, levando à formação de aminas terciárias e boratos. Neste caso, o borano empregado para a redução de amidas terciárias deve apresentar, no mínimo, dois hidrogênios ativos. Esta proposta é evidenciada experimentalmente em reduções de amidas terciárias por diborano ${ }^{35,36}$.

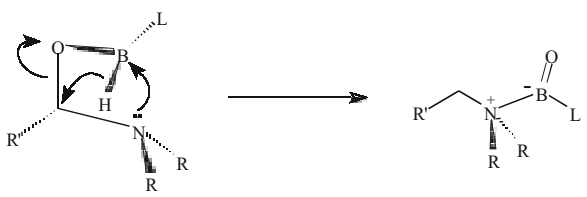

Apesar da possibilidade de formação de um intermediário mais estável por rearranjo, o aumento do volume dos grupos B-substituintes 
e/ou N-substituintes diminui a estabilidade relativa do estado de transição ${ }^{100}$. Entretanto, deve-se ressaltar que o efeito estérico de grupos B-substituídos volumosos, mesmo em tri-arilboranos, não desfavorece interações envolvendo o boro ${ }^{99}$. Por isso, mesmo no caso de boranos volumosos, torna-se provável a formação de um intermediário que apresente complexação entre nitrogênio e o redutor em excesso no meio de reação (Equação 45). Em consequiência, esse intermediário pode proporcionar mecanismos diferentes para hidrogenólise de ligação carbono-heteroátomo, levando à formação de outros produtos de redução de amidas. $\mathrm{O}$ favorecimento da quebra da ligação tanto de $\mathrm{C}-\mathrm{O}$ quanto de $\mathrm{C}-\mathrm{N}$ depende das condições experimentais e das estruturas dos substratos e reagentes.

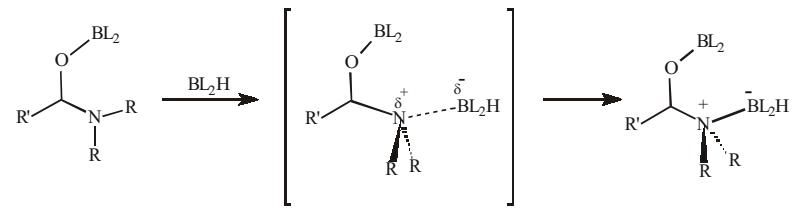

Dessa maneira, além da formação de aminas, o intermediário tetraédrico pode sofrer quebra de ligação carbono-nitrogênio do grupo amido, via ataque intramolecular de hidretos, formando aldeídos que, por sua vez, podem ser reduzidos posteriormente a álcoois. A formação de álcoois e aldeídos, a partir de reduções de amidas, tem sido verificada quando se empregam vários tipos de redutores, principalmente nucleofílicos. Assim, trietilboro-hidreto de lítio reduz amidas terciárias a álcoois primários ${ }^{139}$. $\mathrm{O}$ emprego de $\mathrm{LiAlH}_{4}$ pode proporcionar a quebra redutiva de amidas terciárias, levando à formação de álcoois e aminas secundárias ${ }^{140,141}$. Na redução de N,N-dimetilbenzamida com $\mathrm{LiBH}_{4}$ verifica-se a formação de benzildimetilamina (33\%) e álcool benzílico (58\%), sendo, entretanto, verificada a formação de álcool benzílico em $90 \%$ quando se emprega $\mathrm{LiBH}_{4}-\mathrm{MeOH}-$ $\mathrm{THF}^{66,139}$.

No caso de redutores eletrofílicos, apesar de a redução de amidas contendo grupos $\mathrm{N}$-substituintes ou $\mathrm{C}$-substituintes mais volumosos favorecerem a formação de amina terciária ${ }^{142}$, alquilboranos volumosos favorecem predominantemente a formação de álcoois ${ }^{32,143} \mathrm{e}$ aldeídos $^{30,144}$. Da mesma forma, complexos metal amido-borano convertem amidas terciárias em álcoois primários ${ }^{63,92,93,145}$.

O efeito da concentração do redutor na seletividade da redução pode ser verificado quando se emprega amidoboro-hidreto de lítio $\left(\mathrm{LiH}_{2} \mathrm{NBH}_{3}\right)$. Esse redutor reduz amidas terciárias a aminas quando se utiliza pequena proporção de redutor em relação à amida e, de modo diferente, formam-se predominantemente álcoois quando se utiliza excesso relativo de redutor ${ }^{142}$. Apesar de amidas primárias e secundárias não serem reativas, no caso da redução de amidas terciárias por aminoboro-hidretos (que são precursores de aminoboranos), os efeitos estéricos em ambos os reagentes podem favorecer seletivamente a formação tanto de álcoois quanto de aminas correspondentes (Equação 46; onde Pyrr = pirrolidina $)^{92,93}$.

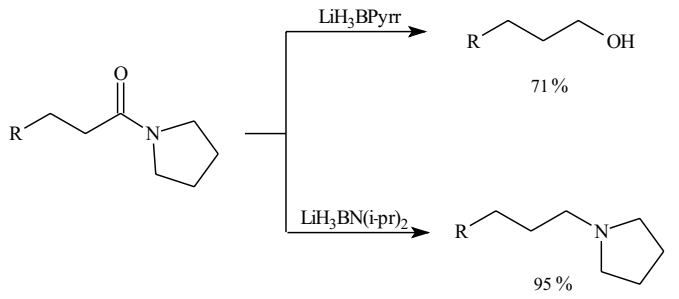

Esses resultados sugerem que o complexo amino-borano do intermediário tetraédrico pode ter um papel importante na etapa poste- rior de redução, conforme verificado, por exemplo, na reatividade de oxazaborolideno-borano durante a redução de cetonas ${ }^{123}$. Assim, a partir desse intermediário, podem ser propostas duas possibilidades de hidrogenólise na redução de amidas. Por mecanismo diferente do descrito na Equação 44, a primeira promoveria quebra da ligação C-O, formando o sal de amônio quaternário (Equação 47) e a amina correspondente, após hidrogenólise. De forma diferente, a segunda resultaria na hidrogenólise da ligação carbono-nitrogênio, formando um alcoxiborano (Equação 48) que, por sua vez, pode levar ao álcool correspondente, após hidrogenólise.

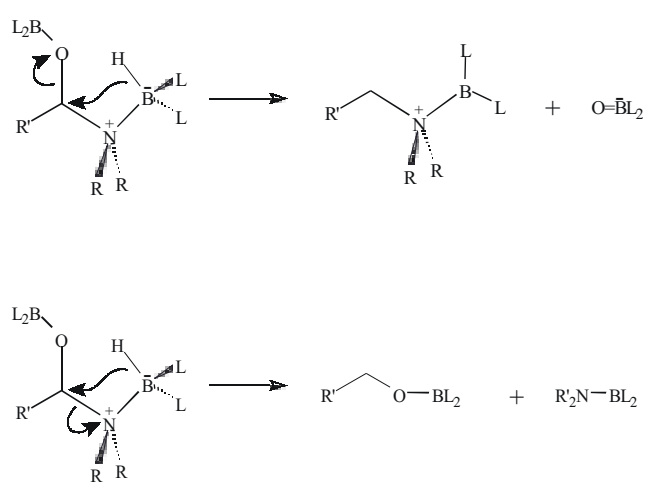

A formação de aldeído como produto da redução de amidas terciárias pode ocorrer pelo ataque nucleofílico de hidretos ao boro ligado ao oxigênio (Equação 49). Isso seria facilitado pela estrutura de um estado de transição cíclico de seis membros, que resulta na regeneração de um equivalente do redutor. $\mathrm{O}$ aldeído formado pode ser reduzido a álcool numa etapa subseqüente.

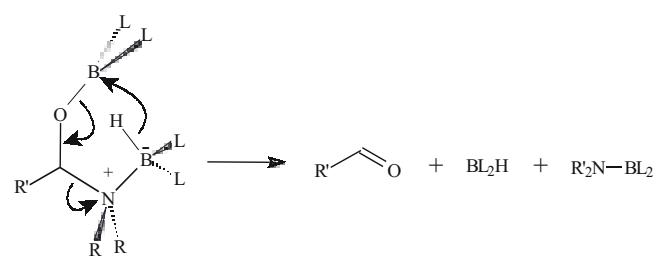

Mecanismo diferente tem sido proposto para redução de amidas terciárias com amino-boranos, conforme Equação $50^{63,130}$. Neste caso, a formação do aldeído, que pode ser reduzido também a álcoois, ocorre pelo envolvimento do oxigênio na hidrogenólise da ligação carbono-nitrogênio, via intermediário tetraédrico complexado com boranos em ambos os heteroátomos.

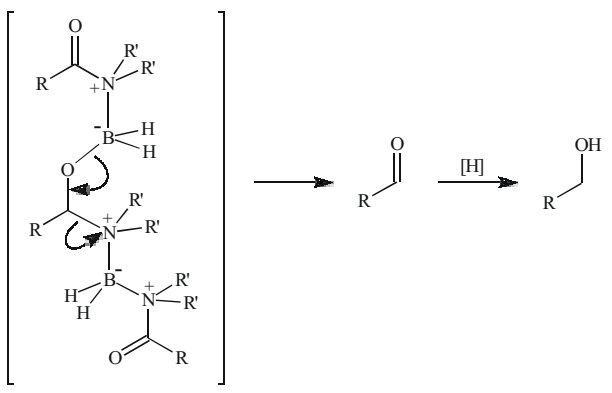

Uma outra possibilidade pode envolver um intermediário cíclico (Equação 51) ${ }^{146}$. Nesse caso, o efeito da tensão anular no intermediário deve ser muito importante para formação do produto pois intermediários com anéis de cinco membros não sofrem reação, conforme Equação 40. 


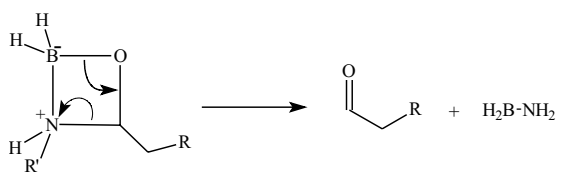

\section{Formação do complexo amino-borano}

Quando se utiliza borano-dimetilsulfeto como redutor, tem sido observado durante a destilação do dimetilsulfeto da mistura de reação que a redução de amidas primárias não requer um equivalente adicional do redutor, inferido pela quantidade de DMS destilado ${ }^{40}$. Com base no número de equivalentes de borano utilizado, o produto resultante contém dois átomos de boro ligados ao nitrogênio, presumivelmente por ligação sigma ou tipo "doador-receptor", sem ocorrer, neste último caso, expansão de coordenação do boro durante a formação do complexo "dipolo-carga" (Equação 52).

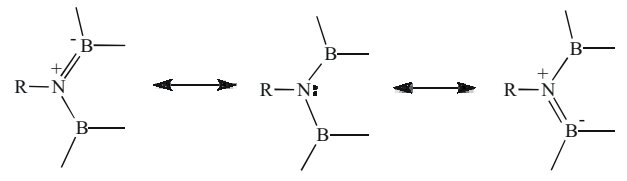

Um comportamento diferente tem sido verificado na redução de aminoácidos aromáticos por diborano. Neste caso, utiliza-se um equivalente adicional de borano por equivalente de ácido devido à formação intermediária de complexos amino-boranos que, por serem menos reativos, desfavorecem outras etapas de redução. Dessa forma, ácido para-aminobenzóico requer oito equivalentes de hidreto ativo do borano, sendo três para a reação com os hidrogênios ativos presentes no nitrogênio e oxigênio, dois para a redução e os três restantes para a formação do complexo amino-borano ${ }^{59}$. Nessa complexação, o efeito eletrônico torna-se secundário, predominando o efeito estérico no nitrogênio que se apresenta ligado a dois átomos de boro e ao grupo arila, que é relativamente muito volumoso.

Por sua vez, após a redução total da ligação $\mathrm{C}=\mathrm{O}$ das amidas secundárias e terciárias, tem-se o consumo de três equivalentes de hidreto para formação do complexo amino-borano (Equação $53)^{39,82,147,148}$. A formação desse complexo é favorecida por ser mais estável do que os outros complexos do borano com solventes presentes no meio de reação, normalmente THF, DMS ou éter etílico $(\mathrm{EE})^{109,128,149,150}$. Além disso, considerando que o comprimento da ligação boro-nitrogênio em complexos amino-borano é essencialmente de ligação simples ${ }^{120}$, pode-se propor que esta ligação apresenta um caráter covalente, explicando sua estabilidade relativa. No meio de reação envolvendo redução de amidas secundárias, a ocorrência do complexo amino-borano é simultânea à evolução de hidrogênio. A formação preferencial deste complexo tem sido verificada quando se utiliza trifluoreto de boro, pois elimina a necessidade de excesso de borano para complexação $0^{40}$.

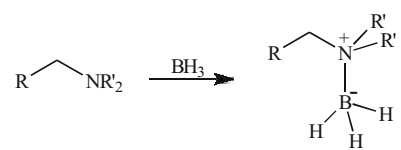

O grau de N-substituição da amida é um fator muito importante na formação e reatividade do complexo amino-borano pois a presença de um grupo alquila ligado ao nitrogênio aumenta sua densidade eletrônica, favorecendo a estabilização, principalmente em aminas terciárias $^{39}$. Isto pode ser evidenciado pelo favorecimento da $\mathrm{N}$ - alquilação de L-prolina empregando borano em piridina, não se verificando redução significativa da carboxila ${ }^{151}$.

No caso de amidas secundárias, as estruturas de ressonância proporcionam intermediários estáveis do tipo borazina ${ }^{150,152}$, favorecendo ligações duplas ou, até mesmo, ligações tríplices entre boro e nitrogênio ${ }^{153}$. A estabilidade térmica destas estruturas depende das restrições estéricas ${ }^{85}$ e eletrônicas ${ }^{154}$ dos grupos B-substituintes. Além disto, pode-se propor ainda que cada átomo de boro, dependendo da estrutura dos grupos substituintes, apresenta-se ligado a dois ou mais átomos de nitrogênio, levando respectivamente a intermediários do tipo di- ou tri-amino-boranos (Equação 54) ${ }^{155}$. Apesar disto, nos produtos de redução de amidas secundárias, o nitrogênio não se apresenta coordenado tão fortemente com o borano como ocorre nas amidas terciárias. Isto pode ser devido ao deslocamento do par de elétrons não-ligante do nitrogênio para o boro, tornando o nitrogênio menos efetivo para complexação ${ }^{39}$, principalmente quando ocorre aumento do volume do grupo N-substituinte ${ }^{156}$.<smiles>[R]CN([R])B(N([R])C[R])N([R])C[Y]</smiles>

De um modo geral, a decomposição do complexo amino-borano é favorecida pela capacidade de complexação do solvente com o borano, pela estrutura dos reagentes complexantes e pelo aumento da temperatura de reação $0^{29,157}$. Além disso, tem sido empregado também iodo para promover a quebra oxidativa do complexo aminoborano na redução de amidas secundárias por borano ${ }^{148}$.

\section{CONCLUSÃO}

Considerando a enorme utilização de boranos na redução de amidas, a falta de propostas sobre os mecanismos desta reação evidencia a sua complexidade. Isto é devido aos diferentes tipos e números de ligações tanto $\mathrm{B}-\mathrm{O}$ quanto $\mathrm{B}-\mathrm{N}$ apresentados nos intermediários, proporcionando alterações em suas propriedades químicas e, conseqüientemente, em suas reatividades para formação dos produtos.

As descrições registradas na literatura permitem propor que as etapas de redução dependem principalmente do grau de N-substituição das amidas e da estrutura destes substituintes, indicando que os efeitos estéricos e eletrônicos no nitrogênio predominam em relação ao oxigênio sobre a velocidade de redução. Embora menos significativo, nos boranos são verificados também efeitos do volume e do grau de B-substituição na reatividade e na determinação dos produtos de reação.

Assim, considerando a predominância do efeito estérico nas reduções envolvendo boranos ${ }^{61,117,158,159}$, a proposição de apenas um mecanismo para reduções dos diferentes tipos de amidas apresentase pouco provável, apesar das características comuns entre amidas primárias, secundárias e terciárias, bem como entre boranos mono-, di- ou tri-substituídos.

Por outro lado, torna-se importante aprofundar o estudo da seletividade nas reduções de amidas, analisando, por exemplo, o efeito da utilização de reagentes contendo hidrogênios marcados e variações na reatividade quando ocorrem alterações estruturais nas bases de Lewis que formam adutos com os boranos, conforme tem sido realizado para reduções de outros grupos funcionais ${ }^{122,160,161}$. 


\section{AGRADECIMENTOS}

Os autores agradecem ao apoio financeiro concedido pela Fundação Coordenação de Aperfeiçoamento de Pessoal de Nível Superior (CAPES) e Conselho Nacional de Pesquisa e Desenvolvimento Científico e Tecnológico (CNPq), bem como pela bolsa de mestrado da CAPES de H. S. Barroso. Os autores agradecem também as considerações dos Prof. Délio S. Raslan e Prof. Massayoshi Yoshida.

\section{REFERÊNCIAS}

1. Langtry, H.D.; Benfield, P.; Drugs 1990, 40, 219.

2. Garrett, R.H.; Grisham, C.M.; Biochemistry; Saunders College Publishing: Orlando, FL, 1995, p 958

3. Foye, W.O.; Lemke, T.L.; Williams, D.A.; Principles of Medicinal Chemistry; Williams \& Wilkins: Media, PA, 1995, p 173-178, 195-247, 856-862.

4. Zhuang, Z.-P.; Plossl, K.; Kung, M.-P.; Um, M.; Kung, H.F.; Nucl. Med. Biol. 1999, 26, 217.

5. Weil, J.A.; Blum, A.; Heiss, A.H.; Kinnaird, J.K.; J. Chem. Phys. 1967, 46,3132 .

6. Isaacs, N.; Physical Organic Chemistry; Longman Singapore Publishers: Singapore, 1995, p 350.

7. SPARTAN: Wavefunction, Inc. 18401 Von Karman, Suite 370, Irvine. (CA 92612, USA)

8. Alcântara, A.F.C.; Piló-Veloso, D.; Nelson, D.L.; J. Braz. Chem. Soc. 1995, 6, 297.

9. Dasadei, M.A.; Rienzo, B.D.; Inesi, A.; Moracci, F.M.; J. Chem. Soc., Perkin Trans. 1 1992, 375.

10. Boulmedais, A.; Jubault, M.; Tallec, A.; Bull. Soc. Chim. Fr. 1988, 610.

11. Shono, T.; Masuda, H.; Murase, H.; Shimomura, M.; Kashimura, S.; J. Org. Chem. 1992, 57, 1061

12. Nishiyama, Y.; Hamanaka, S.; J. Org. Chem. 1988, 53, 1326.

13. Deprez, S.; Tetrahedron Lett. 1987, 28, 4679.

14. Huffman, J.W.; Liao, W.; Wallace, R.H.; Tetrahedron Lett. 1987, 28, 3315.

15. Wojcik, B.; Adkins, H.; J. Am. Chem. Soc. 1934, 56, 2419.

16. Chatgilialoglu, C.; Griller, D.; Lesage, M.; J. Org. Chem. 1988, 53, 3641.

17. Garcia, J.; Vilarraja, J.; Tetrahedron Lett. 1987, 28, 341.

18. Borch, R.F.; Durst, H.D.; J. Am. Chem. Soc. 1969, 91, 3996.

19. Krishnamurthy, S.; Brown, H.C.; J. Org. Chem. 1980, 45, 849.

20. Mandal, S.B.; Giri, V.S.; Sabeena, M.S.; Pakrashi, S.C.; J. Org. Chem. 1988, 53, 4236 .

21. Mandal, S.B.; Giri, V.S.; Pakrashi, S.C.; Synth. Commun. 1987, 17, 1128.

22. Soai, K.; Oyamada, H.; Ookawa, A.; Synth. Commun. 1982, 12, 463.

23. Rahman, A.V.; Basha, A.; Waheed, N.; Tetrahedron Lett. 1976, 17, 219.

24. Walker, E.; Chem. Soc. Rev. 1976, 5, 23.

25. Brown, H.C.; Krishnamurthy, S.; Tetrahedron 1979, 35, 567.

26. Lane, C.F.; Chem. Rev. 1976, 76, 773.

27. Kuehne, M.E.; Shannon, P.J.; J. Org. Chem. 1977, 42, 2082.

28. Ellzey,Jr., S.E.; Mack, C.H.; Connick,Jr., W.J.; J. Org. Chem. 1967, $32,846$.

29. Cha, J.S.; Lee, J.C.; Lee, H.S.; Lee, S.E.; Kim, J.M.; Kwon, O.O.; Min, S.J.; Tetrahedron Lett. 1991, 32, 6903.

30. Brown, H.C.; Krishnamurthy, S.; Yoon, N.M.; J. Org. Chem. 1976, 41, 1778.

31. Wolf, N.J.; Georgiev, E.M.; Yordanov, A.T.; Whittlesey, B.R.; Koch, H.F.; Roundhill, D.M.; Polyhedron 1999, 18, 885.

32. Brown, H.C.; Bigley, D.B.; Arora, S.K.; Yoon, N.M.; J. Am. Chem. Soc. 1970, 92, 7161 .

33. Brown, H.C.; Yoon, N.M.; J. Am. Chem. Soc. 1966, 88, 1464.

34. Yoon, N.M.; Brown, H.C.; J. Am. Chem. Soc. 1968, 99, 2927.

35. Brown, H.C.; Heim, P.; J. Org. Chem. 1973, 38, 912.

36. Newman, M.S.; Fukunaga, T.; J. Am. Chem. Soc. 1960, 82, 693.

37. Alcântara, A.F.C.; Piló-Veloso, D.; Nelson, D.L.; Quim. Nova 1993, 16, 210.

38. Cha, J.S.; Kwon, O.O.; Kim, J.M.; Bull. Korean Chem. Soc. 1996, 17, 725. (CA 125:300173).

39. Brown, H.C.; Choi, Y.M.; Narasimhan, S.; J. Org. Chem. 1982, 47, 3153.

40. Tlahuextl, M.; Martinez-Martinez, F.J.; Rosales-Hoz, M. J.; Contreras, R.; Phosphorus, Sulfur Silicon Relat. Elem. 1997, 123, 5.

41. Pawelke, G.; Buerger, H.; Appl. Organomet. Chem. 1996, 10, 147.

42. Krishnamurthy, S.; Thompson, K.L.; J. Chem. Educ. 1977, 54, 778.

43. Eliel, E.L.; Wilen, S.H.; Mander, L.N.; Stereochemistry of Organic Compounds; John Wiley \& Sons, Inc.: New York, NY, 1994, p 550.

44. Barroso, H.S.; Dissertação de Mestrado; Universidade Federal do Amazonas, Brasil, 2001.
45. Barroso, H.S.; Alcântara, A.F.C.; Resumos da $23^{a}$ Reunião Anual Sociedade Brasileira de Química, Poços de Caldas, Brasil, 2000.

46. March, J.; Advanced Organic Chemistry; John Wiley \& Sons: New York, 1985, p 437

47. Brown, H.C.; Rao, B.C.S.; J. Am. Chem. Soc. 1960, 82, 681.

48. Brown. H.C.; Stocky, T.P.; J. Am. Chem. Soc. 1977, 99, 8218.

49. Burnham, B.S.; Chen, S.Y.; Sood, A.; Spielvogel, B.F.; Hall, I.H.; Pharmazie 1995, 50, 779.

50. Furuta, K.; Miwa, Y.; Iwanaga, K.; Yamamoto, H.; J. Am. Chem. Soc. 1988, $110,6254$.

51. Lane, C.F.; Myatt, H.L.; Daniels, J.; Hopps, H.B.; J. Org. Chem. 1974, 39, 3052 .

52. Gribble, G.W.; Nutaitis, C.F.; Org. Prep. Proced. Int. 1985, 17, 317.

53. Bunton, C.A.; O'Connor, C.; Turney, T.A.; Chem. Ind. 1967, 1835.

54. Bruylants, A.; Kezdy, F.; Rec. Chem. Progr. 1960, 21, 213.

55. Queen, A.; Can. J. Chem. 1967, 45, 1619.

56. Crundon, E.W.; Hudson, R.F.; J. Chem. Soc. 1956, 501.

57. Kornet, M.J.; Thio, P.A.; Tan, S.I.; J. Org. Chem. 1968, 33, 3637

58. Carreño, M.C.; Dominguez, E.; Garcia-Ruano, J.L.; Rubio, A.; J. Org. Chem. 1987, 52, 3619.

59. Brown, H.C.; Krisnamurthy, S.; Stocky, T.P.; J. Org. Chem. 1973, 38, 2786. 60. Brown, H.C.; Rao, B.C.S.; J. Am. Chem. Soc. 1959, 81, 6428.

61. Brown, H.C.; Ramachandran, P.V.; J. Organomet. Chem. 1995, 500, 1.

62. Eisch, J.J.; Adv. Organomet. Chem. 1996, 39, 355.

63. Fisher, G.B.; Fuller, J.C.; Harrison, J.; Alvarez, S.G.; Burkhardt, E.R.; Goralski, C.T.; Singaram, B.; J. Org. Chem. 1994, 59, 6378.

64. Brown, H.C.; Heim, P.; Yoon, N.M.; J. Am. Chem. Soc. 1970, 92, 1637.

65. Nefzi, A.; Ostresh, J.M.; Meyer, J.-P.; Houghten, R.A.; Tetrahedron Lett. 1997, 38, 931 .

66. Soai, K.; Ookawa, A.; J. Org. Chem. 1986, 51, 4000.

67. Krishnamurthy, S.; Tetrahedron Lett. 1982, 23, 3315

68. Brown, H.C.; Narasimhan, S.; Choi, Y.M.; Synth. Commun. 1981, 996.

69. Brown, H.C.; Heim, P.; J. Am. Chem. Soc. 1964, 86, 3566.

70. Brown, H.C.; Kanth, T.V.B.; Zaidlewicz, M.; J. Org. Chem. 1998, 63, 5154.

71. Akabori, S.; Takanohashi, Y.; J. Chem. Soc., Perkin Trans. 1 1991, 479.

72. Fieser, L. F.; Fieser, M.; Reagents for Organic Synthesis; John Wiley \& Sons: New York, 1967, p 588.

73. Kloefkorn, C.; Schmidt, M.; Spaniol, T.; Wagner, T.; Costisor, O.; Paetzold, P.; Chem. Ber. 1995, 128, 1037.

74. Brown, H.C.; Cho, B.T.; Park, W.S.; J. Org. Chem. 1988, 53, 1231.

75. Evans, D.A.; Fu, G.C.; J. Am. Chem. Soc. 1991, 113, 4042.

76. Singaram, B.; Jackson, T.C.; Harrison, J.; Synlett 1996, 383

77. Schick, G.; Loew, A.; Nieger, M.; Ariola, K.; Niecke, E.; Chem. Ber. 1996. 129, 911.

78. Salunkhe, A.M.; Brown, H.C.; Gov. Rep. Announce. Index (U.S.) 1996, 96 , 608. (CA 124:342222).

79. Reddy, C.K.; Periasamy, M.; Tetrahedron 1992, 48, 8329.

80. Dhokte, U.P.; Kulkarni, S.V.; Brown, H.C.; J. Org. Chem. 1996, 61, 5140.

81. Orelli, L.R.; Salermo, A.; Hedrera, M.E.; Perillo, I.A.; Synth. Commun. 1988, 28, 1625 .

82. Nefzi, A.; Ostresh, J.M.; Giulianotti, M.; Houghten, R.A.; J. Comb. Chem. 1999, $1,195$.

83. Holzner, C.; Wagner, A.; Pantke, D.; Block, H.-D.; Moretto, H.-H.; Ohlendorf, W.; GER 4411752, 1995. (CA 124:146468).

84. Padilla-Martinez, I.I.; Andrade-Lopez, N.; Gama-Goicochea, M.; AguilarCruz, E.; Cruz, A.; Contreras, R.; Tlahuext, H.; Heteroat. Chem. 1996, 7, 323.

85. Luthin, W.; Stratmann, J.-G.; Elter, G.; Meller, A.; Heine, A.; Gornitzka, H.; Z. Anorg. Allg. Chem. 1995, 621, 1995.

86. Brown, H.C.; Kanth, J.V.B.; Dalvi, P.V.; Zaidlewicz, M.; J. Org. Chem. 1999, 64, 6263.

87. Andrews, G.C.; Crawford, T.C.; Tetrahedron Lett. 1980, 21, 693.

88. Andrews, C.G.; Tetrahedron Lett. 1980, 21, 697.

89. Nishihara, N.; Takado, T.; Yamaguchi, H.; Nagata, T.; Chem. Abstr. 1997. $125,274918$.

90. Lide, D.R., ed.; CRC - Handbook of Chemistry and Physics; CRC Press, Boca Raton, FL, 1993.

91. Fisher, G.B.; Harrison, J.; Fuller, J.C.; Goralski, C.T.; Singaram, B.; Tetrahedron Lett. 1992, 33, 4533.

92. Fisher, G.B.; Fuller, J.C.; Harrison, J.; Goralski, C.T.; Singaram, B.; Tetrahedron Lett. 1993, 34, 1091.

93. Brown, H.C.; Dhar, R.K.; Ganesan, K.; Singaram, B.; J. Org. Chem. 1992, $57,499$.

94. Schedler, D.J.A.; Godfrey, A.G.; Ganem, B.; Tetrahedron Lett. 1993, 34, 5035.

95. Brown, H.C.; Ganesan, K.; Tetrahedron Lett. 1992, 33, 3421.

96. Ganesan, K.; Brown, H.C.; J. Org. Chem. 1994, 59, 7346. 
97. Brace, N.O.; J. Org. Chem. 1993, 58, 1804.

98. Barone, V.; Adamo, C.; Minichino, C.; J. Mol. Struct. (THEOCHEM) 1995, 330,325 .

99. Lambert, C.; Lopez-Solera, I.; Raithby, P.R.; Organometallics 1996, 15, 452 .

100. Herberich, G.E.; Barday, E.; Fischer, A.; J. Organomet. Chem. 1998, 567, 127.

101. Burns, B.; King, N.P.; Studley, J.R.; Tye, H.; Wills, M.; Tetrahedron: Asymmetry 1994, 5, 801.

102. Fang, D.-C.; Fu, X.-Y.; Chem. Phys. Letters 1996, 259, 265

103. Ward, D.E.; Lu, W.-L.; J. Am. Chem. Soc. 1998, 120, 1098.

104. Gridnev, I.D.; Miyaura, N.; Suzuki, A.; Organometallics 1993, 12, 589.

105. Taniguchi, M.; Fujii, H.; Oshima, K.; Utimoto, K.; Tetrahedron 1993, 49, 11169.

106. Zhang, F.Y.; Yip, C.-W.; Chan, A.S.C.; Tetrahedron: Asymmetry 1996, 7, 2463.

107. Miyaura, N.; Suzuki, A.; Chem. Rev. 1995, 95, 2457.

108. Sibi, M.P.; Cook, G.R.; Liu, P.; Tetrahedron Lett. 1999, 40, 2477.

109. Paikoff, S.J.; Wilson, T.E.; Cho, C.Y.; Schultz, P.G.; Tetrahedron Lett. 1996, 37, 5653.

110. Baumstark, A.L.; Balakrisnan, P.; Dotrong, M.; McCloskey, C.J.; Oakley, M.G.; Boykin, D.W.; J. Am. Chem. Soc. 1987, 109, 1059

111. Giffels, G.; Dreisbach, C.; Kragl, U.; Weigerding, M.; Waldmann, H.; Wandrey, C.; Angew. Chem. Int. Ed. Engl. 1995, 34, 2005.

112. Chandrasekharan, J.; Kamachandran, P.V.; Brown, H.C.; J. Org. Chem 1985, 50,5448 .

113. Wann, S.R.; Thorsen, P.T.; Kreenoy, M.M.; J. Org. Chem. 1981, 46, 2579.

114. Smith, C.R.; Yates, K.; Can. J. Chem. 1972, 50, 771.

115. Benedett, E.; Di Blasio, B.; Baine, P.; J. Chem. Soc., Perkin Trans. 21980 500 .

116. Cox, B.G.; J. Chem. Soc., Perkin Trans. 2 1970, 1780.

117. Ramachandran, P.V.; Brown, H.C.; ACS Symp. Ser. 1996, 641, 84.

118. Prasad, K.R.K.; Joshi, N.N.; J. Org. Chem. 1996, 61, 3888.

119. Gamble, M.P.; Studley, J.R.; Wills, M.; Tetrahedron Lett. 1996, 37, 2853.

120. Holley, W.K.; Ryschkewitsch, G.E.; Koziol, A.E.; Palenik, G.J.; Inorg. Chim. Acta 1995, 239, 171

121. Boudreau, C.; Tillyer, R.D.; Tschaen, D.M.; US pat. 401050, 1995. (CA 125:275408)

122. Rogic, M.M.; J. Org. Chem. 1996, 61, 1341.

123. Douglas, A.W.; Tschaen, D.M.; Reamer, R.A.; Shi, Y.-J.; Tetrahedron: Asymmetry 1996, 7, 1303.

124. Zabicky, J.; The Chemistry of Amides; Willey-Interscience: New York, 1970 p. 795.

125. Abdel-Magid, A.F.; Carson, K.G.; Harris, B.D.; Maryanoff, C.A.; Shah, R.D.; J. Org. Chem. 1996, 61, 3849.

126. Kagano, H.; Itsuda, H.; Yamashita, K.; Nakano, M.; Kobayashi, K.; $J P$ 60902, 1994. (CA 124:201773).

127. Inoue, T.; Sato, D.; Komura, K.; Itsuno, S.; Tetrahedron Lett. 1999, 40, 5379 .
128. Dehmlow, E.V.; Niemann, T.; Kraft, A.; Synth. Commun. 1996, 26, 1467.

129. Puigjaner, C.; Vidal-Ferran, A.; Moyano, A.; Pericàs, M. A.; Riera, A.; J. Org. Chem. 1999, 64, 7902.

130. Prasad, A.S.B.; Kanth, J.V.B.; Periasamy, M.; Tetrahedron 1992, 48, 4623

131. Brunel, J.M.; Buono, G.; Synlett 1996, 177.

132. Tadanier, J.; Hallas, R.; Martin, J.R.; Stanaszek, R.S.; Tetrahedron 1981, 37, 1309

133. Demailly, G.; Solladie, G.; Tetrahedron Lett. 1975, 29, 2471.

134. Orelli, L.R.; Niemevz, F.; García, M.B.; Perillo, I.A.; J. Heterocyclic Chem. 1999, 36, 105 .

135. Rylander, P.N.; Hasbrouck, L.; Karpenko, I.; Ann. N. Y. Acad. Sci. 1973, $214,100$.

136. Alcântara, A.F.C.; Dissertação de Mestrado; Universidade Federal de Minas Gerais, Brasil, 1989.

137. Pelter, A.; Rosser, R.M.; Mills, S.; J. Chem. Soc., Perkin Trans. 11984, 717.

138. Moormann, A.E.; Synth. Commun. 1993, 23, 789.

139. Brown, H.C.; Kim, S.C.; Synthesis 1977, 635.

140. Brown, H.C.; Tukamoto, A.; J. Am. Chem. Soc. 1961, 83, 4549.

141. Micovic, V.M.; Mihailovic, M.J.; J. Org. Chem. 1953, 18, 1190

142. Myers, A.G.; Yang, B.H.; Kopecky, D.J.; Tetrahedron Lett. 1996, 37, 3623

143. Brown, H.C.; Park, W.S.; Taecho, B.; Ramachandran, P.V.; J. Org. Chem. 1987, 52, 5406.

144. Brown, H.C.; Heim, P.; Yoon, N.M.; J. Org. Chem. 1972, 37, 2942.

145. Hutchins, R.O.; Learn, K.; Telbany, F.E.; Stercho, Y.P.; J. Org. Chem. 1984, 49, 2438.

146. Hoshino, Y.; Tanaka, H.; Takeno, N.; Bull. Chem. Soc. Jpn. 1998, 71, 2923.

147. Adachi, K.; Tsuru, E.; Banjyo, E.; Doe, M.; Shibata, K.; Yamashita, T.; Synthesis 1998, 1623.

148. Hall, D.G.; Laplante, C.; Manku, S.; Nagendran, J.; J. Org. Chem. 1999, 64, 698.

149. Sassaman, M.B.; Prakash, G.K.S.; Olah, G.A.; Tetrahedron 1988, 44, 3771.

150. Roth, M.; Paetzold, P.; Chem. Ber. 1995, 128, 1221.

151. Khan, N.M.; Arumugam, V.; Balasubramanian, S.; Tetrahedron Lett. 1996 37,4819

152. Emeleus, H.J.; Wade, K.J.; J. Chem. Soc. 1960, 2614.

153. Luckert, S.; Englert, U.; Paetzold, P.; Chem. Ber. 1996, 129, 361.

154. Kawashima, T.; Yamashita, N.; Okazaki, R.; Chem. Lett. 1996, 213.

155. Blanchard, C.; Framery, E.; Vaultier, M.; Synthesis 1996, 45.

156. Weinmann, W.; Hergel, A.; Deforth, T.; Kraemer, A.; Pritzkow, H.; Siebert, W.; Z. Naturforsch., B: Chem. Sci. 1996, 51, 1104.

157. Ottanà, R.; Maccari, R.; Vigorita, M.G.; Rotondo, E.; J. Chem. Research (S) 1998, 550

158. Peper, V.; Stingl, K.; Thuemler, H.; Saak, W.; Haase, D.; Pohl, S.; Juge, S.; Martens, J.; Liebigs Ann. 1995, 2123.

159. Dyer, U.C.; Brennan, J.J.; GB 2637, 1995. (CA 125:222165).

160. Brown, H.C.; US pat. 5481038, 1996. (CA 124:231842).

161. Brown, H.C.; US pat. 5567849, 1995. (CA 125:301225). 